\title{
Supplement of
}

\section{A numerical modelling study of the physical mechanisms causing radiation to accelerate tropical cyclogenesis and cause diurnal cycles}

5 Melville E. Nicholls ${ }^{1}$, Warren P. Smith ${ }^{1}$, Roger A. Pielke Sr. ${ }^{1}$, Stephen M. Saleeby ${ }^{2}$ and Norman B. Wood $^{3}$

${ }^{1}$ Cooperative Institute for Research in Environmental Sciences, Department of Atmospheric and Oceanic Sciences, University of Colorado, Boulder, CO 80309, USA

${ }^{2}$ Department of Atmospheric Science, Colorado State University, Fort Collins, CO 80523, USA

$10 \quad{ }^{3}$ Space Science and Engineering Centre, University of Wisconsin, Madison, WI 53706, USA

Correspondence to: Melville E. Nicholls (Melville.Nicholls@colorado.edu) 


\section{S1 Cloud experiments}

In this section we first try to understand how radiation was responsible for the very large nocturnal increase in hydrometeor mass between $57 \mathrm{~h}$ and $69 \mathrm{~h}$ shown in Fig. 1b. The vapour mixing ratio and temperature was horizontally averaged for a radius less than $200 \mathrm{~km}$ at $57 \mathrm{~h}$ for the full physics simulation. Experiment 6 uses this average thermodynamic profile and a

5 cloud is initiated with a low level warm and moist bubble. The bubble was produced by applying a heat and moisture source for $300 \mathrm{~s}$ and had peak anomalies of approximately $1.5 \mathrm{~K}$ and $2 \mathrm{~g} \mathrm{~kg}^{-1}$. For Experiment 7 the changes in the horizontally averaged vapour mixing ratio and temperature for a radius less than $200 \mathrm{~km}$ between $57 \mathrm{~h}$ and $69 \mathrm{~h}$ for Experiment 3 was calculated and are shown in Figure S1a. During this $12 \mathrm{~h}$ period radiative forcing caused a moderate increase in the tropospheric moisture with a maximum of $\sim 0.5 \mathrm{~g} \mathrm{~kg}^{-1}$ at low-levels. Between $1-8 \mathrm{~km}$ the temperature decreased by

10 approximately $-1 \mathrm{~K}$. These changes were added to the profile used for Experiment 6 to create the modified profile used for Experiment 7. Results for the hydrometeor mixing ratio and vertical velocity for these two experiments at 45 mins are shown in Figure S2. Evidently the modified thermodynamic profile produces a much stronger convective cell confirming that the nocturnal radiative forcing is indeed capable of having a major effect on convective activity.

Figure S3a shows the accumulated precipitation for Experiments 6, 7, 8, 9, 10 and 11. Experiment 6 has the least

15 precipitation whereas Experiment 7 has the most. Experiment 8 that only includes the vapour change due to radiative forcing has moderately more precipitation than Experiment 6, while Experiment 9 that only includes the temperature change has much more. As well as the temperature change shown in Fig. S1a affecting static stability and CAPE, it will also affect relative humidity. For instance, the initial relative humidity changes for Experiment 9 are larger by approximately 5\% through most of the troposphere compared to Experiment 6. Increasing the humidity is likely to reduce the detrimental effect

20 of dry air entrainment from the surrounding environment on a developing updraft. Moreover CAPE, which is calculated for a parcel lifted from a height of $158 \mathrm{~m}$ above the surface, increases from $1261 \mathrm{~J} \mathrm{~kg}^{-1}$ for Experiment 6 to $1560 \mathrm{~J} \mathrm{~kg}^{-1}$ for Experiment 9, which is likely the main reason the convection is significantly stronger. While the vapour change causes a moderate increase in precipitation when acting alone it is notable that in conjunction with the temperature change it can lead to a very significant increase. Experiment 10 that has the environment radiative forcing produces almost as much

25 precipitation as Experiment 7 that has the full forcing, whereas Experiment 11 that has the core forcing produces only a small increase.

Turning now to examine why there was previously a decrease in the total hydrometeor mixing ratio during the daytime a simulation was conducted with the averaged thermodynamic sounding at $47 \mathrm{~h}$ and compared with a simulation having the changes to water vapour and temperature that occurred in the imposed radiation simulation between $47 \mathrm{~h}$ and $55 \mathrm{~h}$ portrayed

30 in Fig. S1b. Note that a shorter $8 \mathrm{~h}$ period was considered for the daytime because during the dawn and evening hours when the sun is low in the sky the longwave cooling dominates the shortwave warming. During this period the most notable changes were a slight moistening aloft with a peak of just over $0.2 \mathrm{~g} \mathrm{~kg}^{-1}$ at a $\mathrm{z}=7.5 \mathrm{~km}$, a cooling peak of about $0.7 \mathrm{~K}$ at 9 $\mathrm{km}$, and above a warming peak and a stronger cooling peak. It can be seen in Fig. S3b that the cloud simulation that 
included these modifications (Experiment 13), produced almost the same precipitation as the simulation that used the averaged thermodynamic sounding at $47 \mathrm{~h}$ (Experiment 12). This means other factors need to be considered to explain the reduced daytime convective activity. It is worth noting that there is a loss of low level ascent during the daytime (Fig. 7b) compared to the nighttime (Fig. 6b) so it is less likely that the daytime radiative forcing will trigger new convection at low-

5 levels. Another consideration is the effect cold pool outflows have on reducing CAPE and influencing subsequent convective activity. 


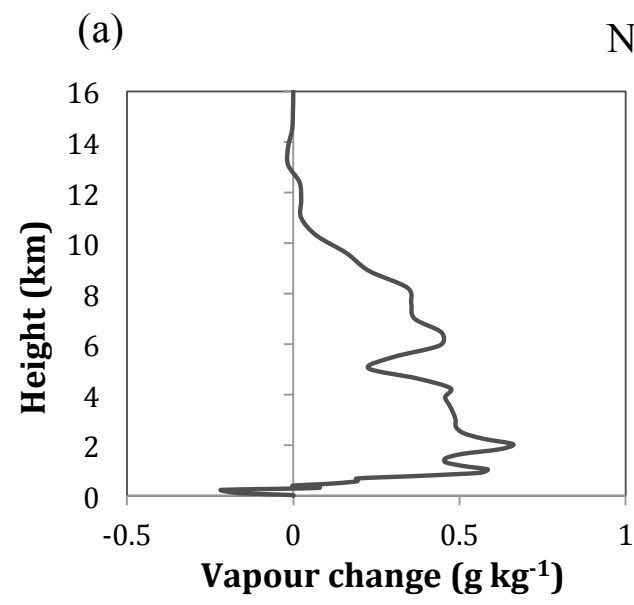

NIGHTTIME

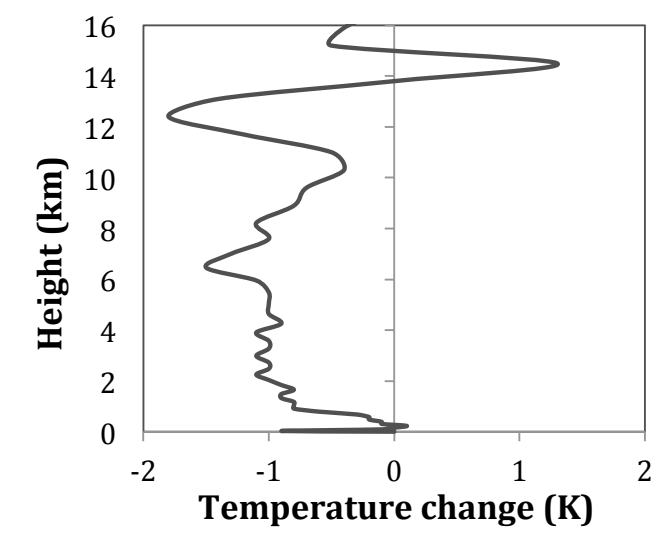

(b)

DAYTIME
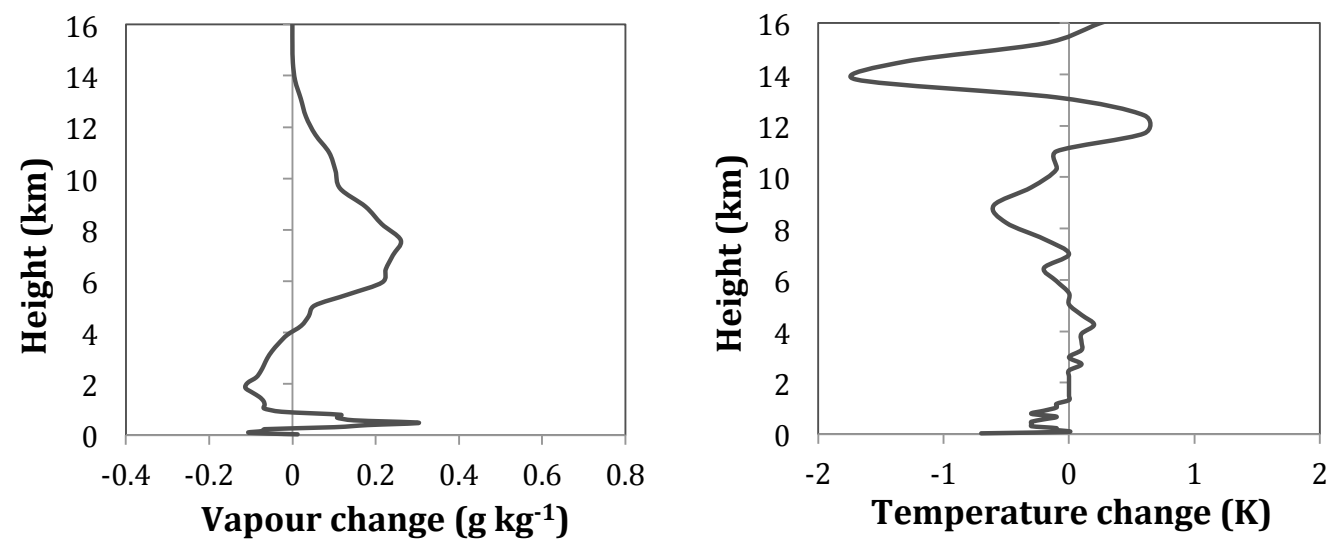

Figure S1. Changes to the vapour and temperature profiles caused by imposed radiative forcing between (a) $57 \mathrm{~h}$ and $69 \mathrm{~h}$ (Experiment 7) and (b) $47 \mathrm{~h}$ and $55 \mathrm{~h}$ (Experiment 13). 
(a) Hydrometeor mixing ratio $57 \mathrm{~h}$

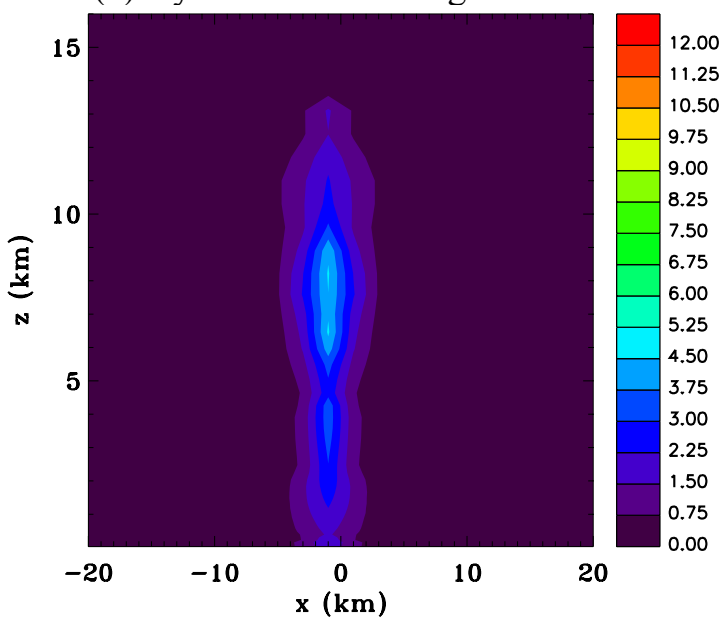

(c) Hydrometeor mixing ratio modified

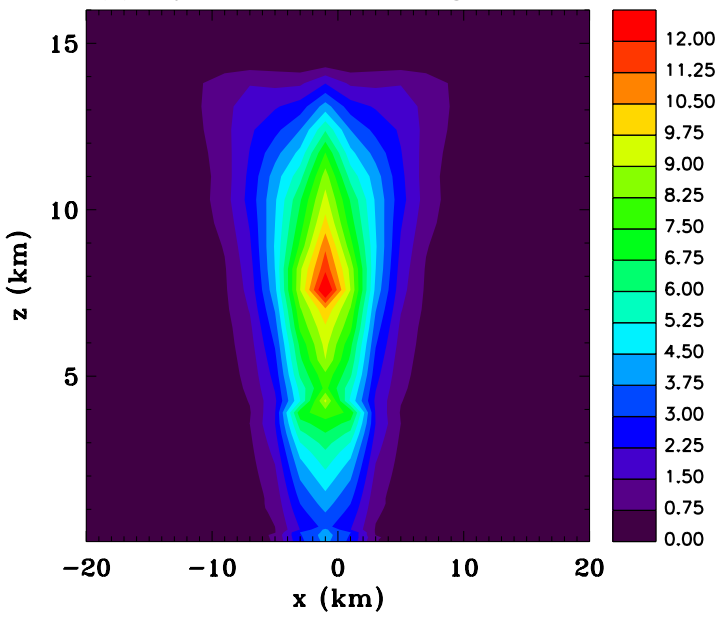

(b) Vertical velocity $57 \mathrm{~h}$

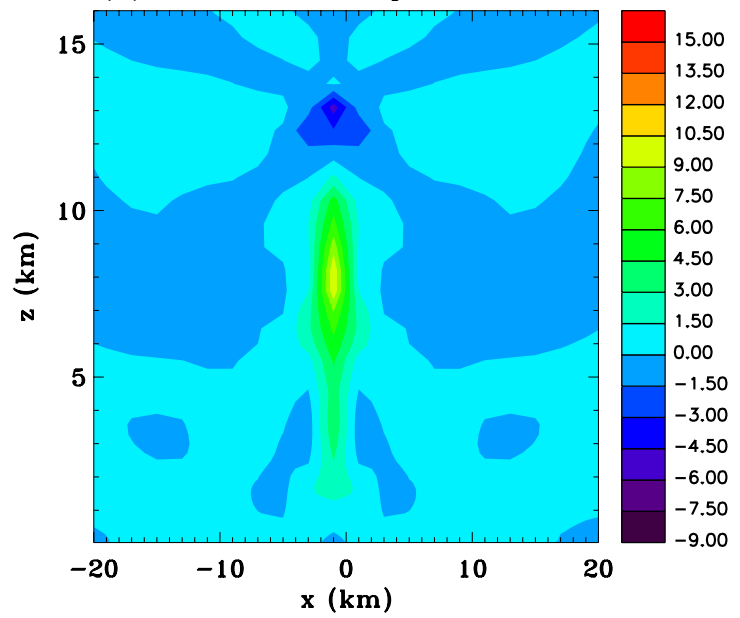

(d) Vertical velocity modified

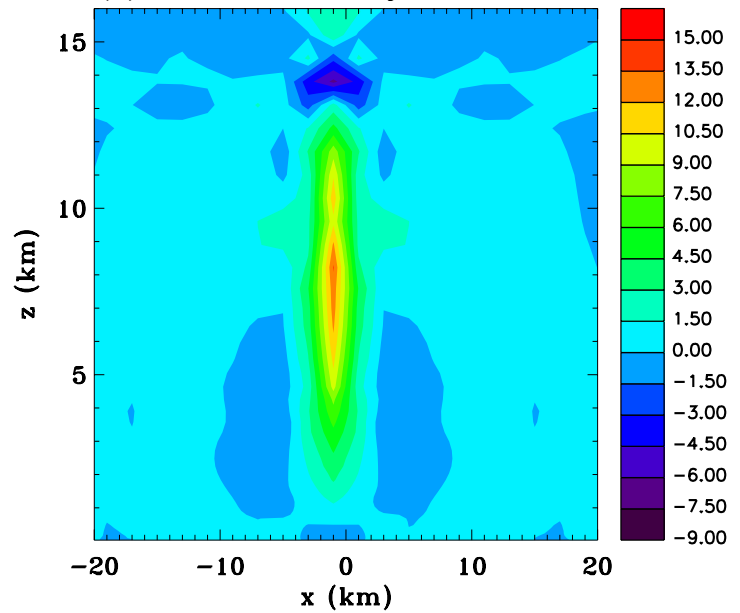

Figure S2. Vertical sections through the centre of the domain at 45 mins for Experiments 6 and 7. (a) Hydrometeor mixing ratio $\left(\mathrm{g} \mathrm{kg}^{-1}\right)$ for Experiment 6, (b) vertical velocity $\left(\mathrm{m} \mathrm{s}^{-1}\right)$ for Experiment 6 , (c) hydrometeor mixing ratio $\left(\mathrm{g} \mathrm{kg}^{-1}\right)$ for Experiment 7 and (d) vertical velocity $\left(\mathrm{m} \mathrm{s}^{-1}\right)$ for Experiment 7 . 
(a) Nighttime radiative forcing $(57 \mathrm{~h}-69 \mathrm{~h})$

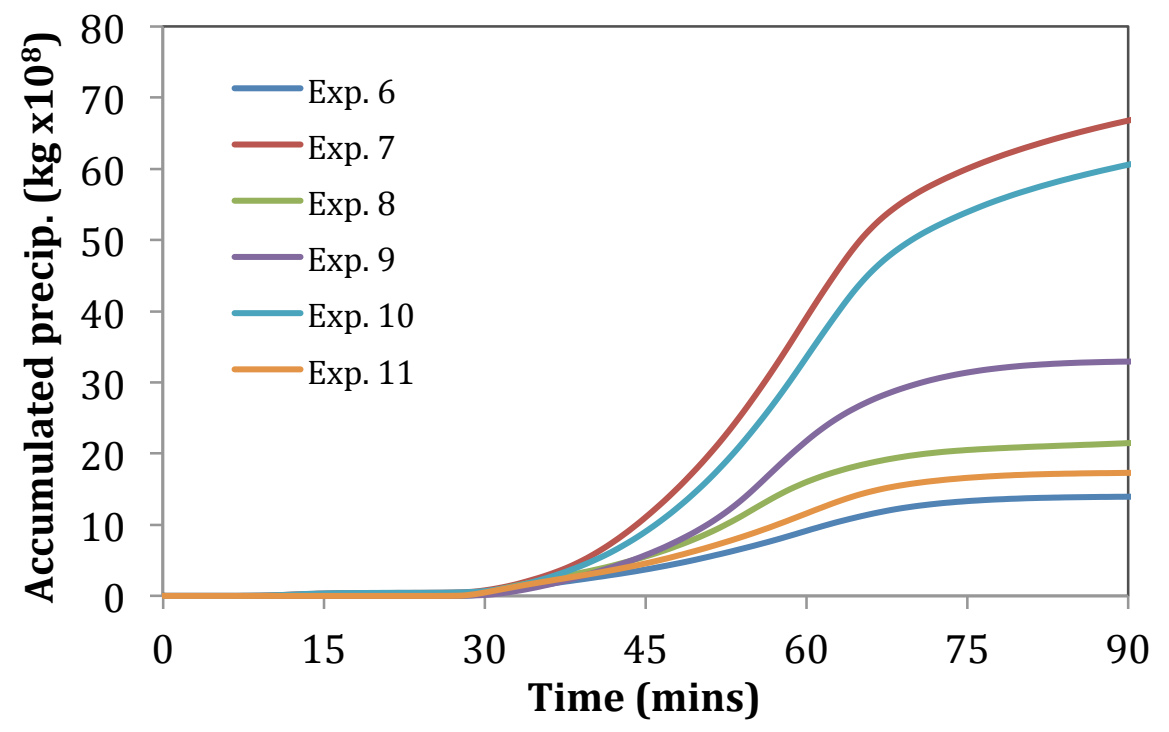

(b) Daytime radiative forcing $(47 \mathrm{~h}-55 \mathrm{~h})$

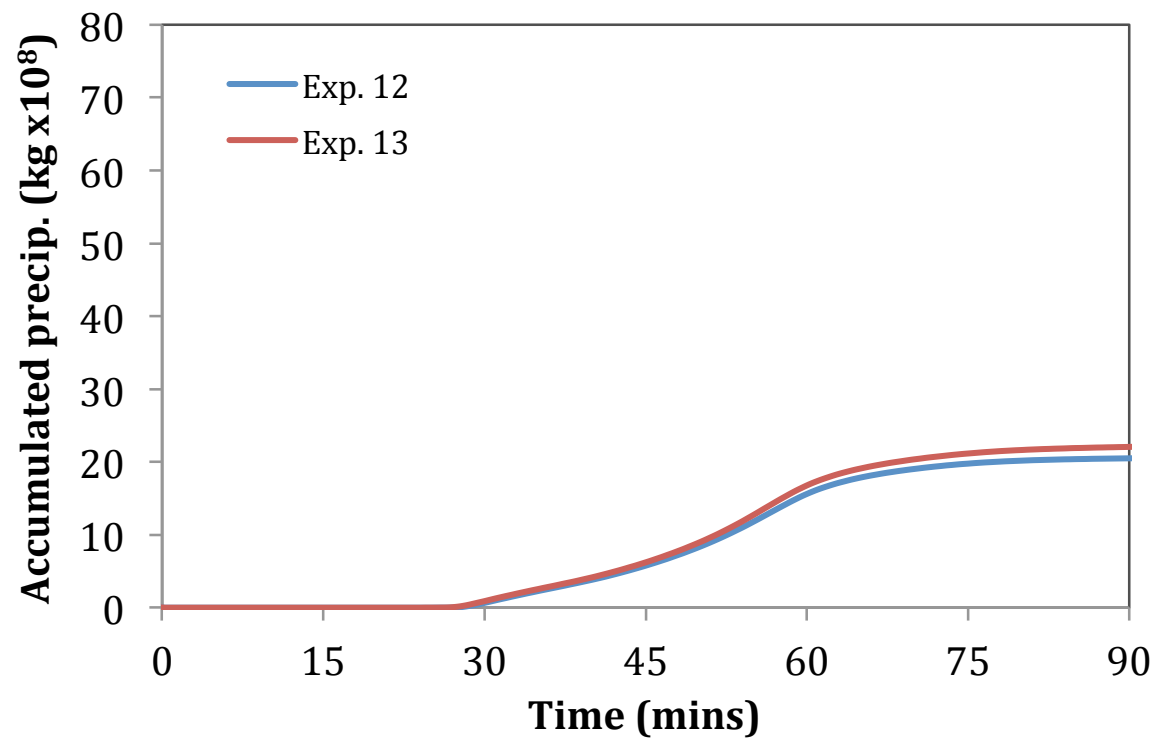

Figure S3. Time series of the accumulated precipitation for the cloud experiments: (a) Experiments 6, 7, 8, 9, 10 and 11, which examine nighttime radiative forcing between $57 \mathrm{~h}$ and $69 \mathrm{~h}$, and (b) Experiments 12 and 13, which examine daytime radiative forcing between $47 \mathrm{~h}$ and $55 \mathrm{~h}$. 